\title{
Power in All Its Forms: Women's Political Participation, Activism, and Advocacy to Promote Gender Equality Facilitated by International Development Volunteers
}

\author{
Rika Mpogazi
}

\section{Introduction}

International development is a broad undertaking that encompasses a series of processes that require cooperation between individuals from many communities. Most importantly, it helps build linkages between local and international organizations in their pursuit of common development goals. In recent decades, one of the most important strides towards positive global development has been through the promotion of Gender Equality and Women Empowerment (GEWE). Eliminating gender biases and barriers to the development of women in order to enable them to achieve their full potential has therefore become a central principle of many development initiatives.

In this paper, the elements that are conducive to the successful achievement of GEWE will be presented through the evaluation of international development volunteers' (IDVs) contributions to women's political engagement, activism, and advocacy. Veritable political participation is not limited to the domain of state-led high politics; it can also manifest through active collaboration with informal networks and non-governmental organizations (NGO) or collectives. The analysis provided in this paper seeks to highlight the ways in which IDVs provide additional support to the local initiatives' efforts to enable women to yield power within their communities, whichever way they choose to define said 'power'. It identifies the various ways in which women utilize the often-limited tools at their disposal to create unique models of leadership that are representative of their specific needs and that of their communities.

\section{Literature Review}

Foucault's notion of true power as it pertains to empowerment implies "the exercise rather than possession of power", meaning that it can take many implicit forms (Parpart/Rai/Staudt 2002). This is of particular importance when analyzing political leadership as the act of molding society can also be done using the realm of society and culture through immaterial or abstract means. Empowerment therefore indicates an empowerment of self through "individual conscientization" and the empowerment of others through the mobilization of a collective and their resources (Parpart/Rai/Staudt 2002: 5). When looking at local scenarios we must 
also consider the interrelation that exists between local and global economic, political, and cultural forces.

The scope of women's political engagement is subjective to the form of political structure of each country. In Senegal, for example, as is the case in many other countries in Africa, a decentralized form of governance can often complicate the process of political participation. It is also said to perpetuate the legacy of colonialism through a continuation of the hierarchical and non-accountable political "patronage" that enabled designated local representatives to be in service of, and only answerable to the central power, the state (Patterson 2002). More specifically to women, the decentralization of power shuffles the players around the political board but keeps the gender inequality firmly intact as women often lack opportunities to penetrate the patriarchal patronage circle. Even the minority of women who manage to acquire a seat at the table are often expected to serve the interests of their male party leaders in order to maintain their seat. The few who remain firm in their accountability towards the needs and interests of women often lack resources and support to do so (Patterson 2002).

In addition, women's leadership and engagement are not restricted to party politics. In fact, many urban women yield power through their involvement in "educational institutions and the workplace" (Patterson 2002: 493). Others, mainly rural women, have sought to provide resources for their communities through the creation of grassroot credit funds and mutual aid, rather than depending on government assistance. Similarly, in Tanzania and Uganda, women's urban associations became a vehicle for solidarity in the pursuit of gender equality and inclusivity, since women have historically been excluded from formal political structures. Their associational life was born out of necessity due to the increasing double burden taken on by women who found themselves occupying the roles of reproductive and productive work during times of economic crisis or civil unrest (Tripp 1994). The output resulting from this social mobilization includes the creation of "income-generating activities, savings and the provision of social services such as daycare" (Tripp 1994: 108). This form of social and political assistance can be described as 'informal volunteering' as it is not coordinated by a larger-scale network of governmental or non-governmental organizations but that delivers support to their community nonetheless (UN Volunteers 2018: 101).

Civil society and voluntary engagement represent less-insulated, more on-theground alternatives to public service that are often embodied by local NGOs, thus encouraging a partnership between international development agencies and domestic civil society in the common pursuit of development objectives (Kamruzzaman 2018). In many cases, NGOs are an essential component of this process. As Kamruzzaman (2018: 72) asserted, “the NGOs' activities can be seen in all sectors of the country, society is benefiting from NGOs, and NGOs are benefiting from 
the social support". This is one of the motivating factors behind the incorporation of local NGOs to international non-governmental organizations (INGOs) as their local presence and practical knowledge help effectively and appropriately adapt global discourses to local contexts (Kamruzzaman 2018).

A study on political advocacy activity in the non-profit sector identified that successful strategies used to influence public policy include "lobbying in the Parliament; activity vis-à-vis government agencies, local authorities, and the media; initiating legislation; research and dissemination of information; and protest" (Schmid et al. 2008: 595). This study also revealed that development practitioners who worked in women's organizations had the most significant impact in all areas related to empowerment through media advocacy (Schmid et al. 2008). The study further indicated positive correlation between the number of international volunteers engaging with these organizations, and the output of political activity and policy prescriptions presented to local governments (Schmid et al. 2008). However, an IDV's ability to succeed in delivering appropriate support to the community or group they are servicing is dependant on their degree of critical reflexivity.

Critical reflexivity refers to the "complex relationship between processes of knowledge production, contexts of such processes, and involvement of producers" (Collier/Muneri 2016: 640). In other words, one must reflect on their positionality in relation to the cultural and social context in which they find themselves and their willingness to include the perspectives of local actors in their capacity building activities. The application of this framework allows for a de-colonization of the spaces in which Western and non-Western actors interact by allowing for a horizontal relation of knowledge sharing. The following section presents the research methods and findings that demonstrate the importance of critical reflexivity in relation to the analysis of GEWE in an international context.

\section{Methods}

Interviews were conducted in 2018 - 2019 with 150 partner organization staff in ten countries. Once all interviews were transcribed, data were coded to identify common themes throughout. Data were analyzed using discourse analysis. The introduction to this special edition has more detailed information on the methodology for data collection and the analysis of findings.

\section{Findings}

In this section, I consider findings across the transcribed data from ten countries as it pertains to political empowerment of women. Major themes emerge from this analysis of the data: the role of transnational actors (IDVs) in providing diverse mentorship and social support roles that promoted women's political engagement; 
the role of transnational actors in the conscientization, critical reflexivity, and mobilization of civil society on gender related issues through research assistance; and critical insights into transnational feminist approaches that reflect an adaptive (and localized) strategy to encourage local women's political agency.

I will highlight the ways in which IDVs help support local partners by bringing awareness to the cause for which they are advocating and by providing empirical evidence to enhance the call for GEWE. I will also touch upon themes of privilege, power and positionality, as well as the notion of the glocalization of gender equality, meaning the formulation of NGO networks between local and international entities in order to recognize, value, and enhance the support to local or national GEWE initiatives on a global level. In this regard, throughout the text, I will explore the different interpretations of formal vs. informal forms of volunteering and political engagement as they relate to the way that women all over the world reinterpret 'power' and challenge the status quo in order to build a more inclusive and sustainable future for generations to come.

\subsection{Bringing Awareness to the Cause}

One of the most effective ways to bring about large-scale political change is by informing the public and bringing awareness to the issues for which political actors are advocating for. In this regard, IDVs are most helpful as they provide social support through role modelling, mentorship, and workshops that enable women's political engagement to flourish in their respective communities.

In recent years, communication technology (whether through the widespread use of the internet or the expansion of social media applications) has enabled us to have access to information from a wider distance and at a more rapid pace. As a result, international and national advocacy efforts have shifted to the digital space. In this regard, IDVs provide digital marketing assistance for numerous campaigns and capacity building initiatives aimed at bringing awareness on gender-related issues in a way that integrates these perspectives into everyday local activities. Social media advocacy increased the reach of local socially and politically engaged women's causes, thereby increasing their ability to place the need for an acknowledgement of women's equal rights and women's economic independence on wider platform (Schmid et al. 2008). This has the effect of calling upon local and national political representatives to respond to their needs by placing gender-related issues firmly on the agenda by working together with women's organizations to formulate policies that would help achieve gender equality in all sectors.

In Ghana, a local actor remarked: "[most] of [their] international volunteers supported [them] to use social media to highlight the issue of women in [their] work." Similarly, another local actor from Tanzania adds: 
[the] digital marketing was [a volunteer]'s idea. She participated on these programs on building capacity on gender and training on standards. It enhanced marketing. Specific tools on the social media, so much of IT. Like, teaching people how to do sponsored ads. How to design their ads, how to customize their ad to be seen in a specific environment to reach specific people.

IDVs also provide psychosocial support to women in the form of mentorship and role modelling. This useful input exposes the local public to a diversity of perspectives on women's rights and gender relations, which effectively elevated the existing efforts of women's social, economic, and political organizations.

In Malawi, a female senior staff member at an international humanitarian organisation pointed out:

the fact that [they] have volunteers that are women in itself is a positive attribute because [she is] hoping that by a representative being a woman, by a protection officer being a woman a small refugee girl sitting in the camp would say 'I want to be that woman', and that alone is the perception gone that women cannot be leaders, women can not be bosses or women can not do this.

This interviewee added that volunteers have "a positive impact on the community regardless of [their] race or [their] gender."

Similarly, in Kenya, a male senior staff member at a community centre says that mentorship provides

psychosocial support to these [local] women, [since] these are women who used to think that they are down [low self-esteem] whatever so they used to kind of come [volunteers] make some kind of jokes or give stories, you see such kind of thing and then [local women] feel motivated and even they get a lot of energy to do what they want to do.

This form of support provided by IDVs has a lasting and transversal effect on participants as it enhances their ability to tackle many challenges related to GEWE on both a professional and personal level.

\subsection{Providing Empirical Evidence to Enhance Women's Empowerment}

On a more practical level, IDVs also apply a more participative approach to development by providing political support and opportunities to enhance economic empowerment for women. Volunteers work alongside women through training sessions and workshops, which led to an increased mobilization and participation of civil society on gender related issues.

One IDV based in Senegal is said to have been: 
given the task of setting up the monitoring at the level of each member-State in order to develop the national action plan, because [the organization] already have a canvas for the development of the action plan, which the country adopts according to the realities on the ground. [The volunteer] shared the draft of the plan of action for the monitoring mechanism that must be put in place in terms of reference, it also follows until these two products exist in each country.

In Malawi, during a community level election an international volunteer is said to have been "quite instrumental together with some of the nationals to ensure that nominations were equal for men and equal for women, different ballots for men as well for women so that [they] could have equal presentation." This supports the notion that IDVs also supply local organizations with empirical evidence to support the need for women's empowerment and political leadership. It demonstrates a joint advocacy effort between international and local actors in the pursuit of gender equality.

In Senegal, a program director for a local women's rights organization network acknowledged that a female IDV's input enhanced their gender strategy, capacity-building by contributing to the development of the legal tool: "Additional Act for Equality of Rights between Women and Men in the CEDEAO space." Further, this IDV also contributed to "the capacity-building of member-State organisations, in trainings that [they] had to organise for the member organisations and even for [their] staff."

In Uganda, a female IDV "decided to write a paper and after three years [of volunteering] she came back with a paper and research, and she's been able to create a program to [prevent] that violence in [precarious] settings."

In Malawi, an IDV conducted an audit on how recruitment of staff is focusing on gender equality. The interviewee noted that the audit's final report "can be used in the planning and even justifications in the creation of some positions and even on how [local employers] can improve gender equality interventions in various sectors." As a result, the development of knowledge helped create "baselines for gender disaggregated data baselines and monitoring and evaluation."

This political support provided by IDVs enabled local organizations to receive the attention of governmental representatives who are better equipped to thereafter provide support on GEWE and appeal to the general public by utilizing their state legitimacy to legitimize the call to action. This shift then has a domino effect on both a local and global level, which we will explore in the upcoming section. 


\subsection{The Glocalization of Gender Equality}

Globalization has increased local and international communities' interconnectedness which has helped facilitate the pursuit of gender equality on a global scale. Yet, the input of local civil society remains fundamentally instrumental to the execution of development activities. This justifies the formulation of NGO networks that coordinate their collective development efforts in a way that accommodates the needs of both the international and local participants (Kamruzzaman 2018). It also highlights the interdependence between global and local frameworks. However, many local, regional, and national initiatives that encourage women's political representation and participation (through politics and otherwise) have been put in place long before the arrival of IDVs. International institutional policies and frameworks are said to have provided a source of inspiration for local gender equality and women's empowerment initiatives. Many gender mainstreaming programs and policies are adapted to local frameworks to stimulate women's political participation and advocacy efforts. "We share similar [gender-related] views than that of the international community, here in Africa," remarks a Senegalese female senior member of a regional economic network. This interviewee explained further that the "powerful civil society organizations" address inequality by aligning interventions and subsequent indicators with international indicators as outlined in the UN's Sustainable Development Goal \#5 and international conventions such Convention on the Elimination of all Forms of Discrimination Against Women (CEDAW) using these frameworks as references in interventions.

In addition to international influence, there is also strong local support for political participation. In Senegal, for example, gender parity is a requirement during elections:

Senegal is one of the few African countries to have signed the Total Power Parity Law on election-related instances, which means that in all election processes, the number of women must be equal to that of men, even if there are a few regressions on the part of the General Assembly, but at a certain point, we were almost at a level of total parity," according to the director of an employment agency in Dakar's outskirts.

Signed in 2010, this law "obliges all political parties to place women and men in an alternating matter on candidate lists, aiming at a male-female ratio of $50 \%$ " thereby institutionalizing the equal representation of men and women in all governing bodies" (Tøraasen 2017: 2).

Moreover, in many countries where partner organizations operate, the state constitution reserves "special seats...for marginalized groups [such as] ...women as well as the youth," as noted by a senior staff member at a development NGO in Kenya. 
Political mobilization is an essential step to the empowerment of women as it allows them to have access to a larger platform where they are able to express their needs and desires. IDVs support in the formulation of similar legal and political has opened up a space for local actors to inscribe their development goals in the code of law. However, not all GEWE initiatives take place in a formal structure, as we'll see in the next section, sometimes political moves can be undertaken outside the realm of politics.

\subsection{Valuing 'Informal' Volunteering}

Political engagement does not always have to be through the domain of high politics, it also implies leadership roles within existing framework linked to economic governance, women's leadership, and representation to name a few. Despite the recent institutionalisation of gender parity in formal government bodies, women's social mobilization is equally effective through grassroot organizing. In fact, women's associations often substitute the lack of state welfare and wanning resource allocation by providing the social servicing and the tools necessary for women to empower themselves (Tripp 1994: 108).

A local development actor in Vietnam remarked that the implementation of public servicing is waning in certain areas: "The overall problem of Vietnam is that we have laws, but the implementation is bad, and it doesn't really work very well when we come lower and lower levels." This form of social and political assistance can be described as 'informal volunteering' as it is not coordinated by a larger-scale network of governmental or NGOs but that delivers support to their community nonetheless. The fact that women participate in informal volunteering more often than men is a testament to the ways in which women are often excluded from the formal fabric of volunteer networks and lack access to public resources that would help give value to their invaluable work (Lough et al. 2018).

Despite claims of exclusionary membership, women's organization based on informal, communal, political, and economic linkages have proved to be anything but biased. Many volunteer initiatives by local women's organizations are unique in that they are able to mobilize women of various backgrounds under a common objective, regardless of their ethnicity, religious affiliation, or socio-economic level (Tripp 1994). These local women's associations' unique political engagement and advocacy are therefore essential to the advancement of GEWE on a more grassroots level.

\subsection{Critical Reflexivity in International Relations}

Despite the positive international support, many local development actors also express a need to restructure the Western feminist model in order to create 
authentic frameworks, reflective of local dynamics, allowing for an adaptive strategy to enhance local women's political agency. This recalls the need for critical reflexivity in the exchanges between international and local actors (Collier/Muneri 2016). It is important to make an explicit effort to decolonize the practice and the space in which development efforts are taking place. In order to better service the communities the international support is intended for, IDVs are advised to recognize their position of privilege by reflecting on their positionality. This means critically reflecting on one's intersectionality, meaning one's social position within a collective or society as it relates to their race, ethnicity, faith, education, sexual orientation, income-level, geography, (dis)ability, etc. These social positionings outline the power relations that exist between or within groups and can be a definitive factor of influence over the outcome of a development initiative.

The interpretation of gender equality varies from one context to another. In Peru, for example, a female staff member at a development NGO says that their work focuses of gender equality and the promotion of Indigenous women's rights, a social group that face "a specific kind of discrimination, which a whole other thing to work on."

Additionally, in many contexts' local religious leaders and conservative groups who directly or indirectly reinforce the patriarchal gender norms pose a threat to feminist women's empowerment initiatives. Accounts of these obstacles were noted by local volunteers in Tanzania and Peru as a local actor in Tanzania points out that "[i]n rural communities, religious leaders have a lot of power and they can make change," while another remarks that "it is very challenging to change community traditional beliefs, so it is a process to bring feminism issues in the community." Similarly, a female staff member at a development NGO in Peru echoes these sentiments by mentioning that the most notable barriers to the achievement of their goals are posed by conservatives and fundamentalists and that their work focuses on "defending the gender focus that has started to be present in the State and to defend [their] rights from these fundamental groups."

Many local actors recommend that IDVs make an effort to adapt to local culture in order to create a framework that is reflective to local needs. Failure to do so could otherwise result in "culturally incongruous directives that fail to account for local social dynamics" (Lough et al. 2018: 69). A local development actor in Uganda mentions this during an interview:

The facts are real but the implementation in our culture has not worked. For example, when you talk of Canada and the USA or wherever we hear that rights are respected $100 \%$ but here you have to be patient. You have to be patient for the sake of your family, for the sake of your marriage, for the sake of your children. So here women tend to suffer for the sake of their marriage, our 
relatives and our children over their own empowerment and rights. I think it's problematic in terms of its implementation, as it doesn't take into consideration Ugandan culture. We do talk about gender and equality and feminism, but it remains problematic.

If gender equality is the ultimate goal, reciprocity is key. "Yes, it's 50/50. It's twoway traffic. That is something we have noticed. We learn from them a lot, and they learn from us a lot", summarizes a local development actor in Tanzania. Mutual support between international and national volunteers is essential to the cohesion of various development goals. When IDVs reflect on their positionality and seek out ways to adapt or adjust their vision of development to fit the context in which they work, they are essentially restoring the power of decision-making in the hands of local actors for whom the support is intended for. This essential reflection on the importance of equity in the distribution of power requires us to also critically rethink the very notion of power and the ways in which it is exercised in a variety of contexts and by a variety of actors.

\section{Analysis}

Gender Equality and Women's Empowerment initiatives draw attention to the power dynamics that exist within a society. Yet it is important to recall that power, as a means rather than an end, is relative, since it is expressed in various forms and results in a multitude of outcomes. When evaluating women's ability to exercise power, one must also consider the informal and immaterial or abstract tools women have access to, in order to draw a fuller, more holistic portrait of their empowerment of self and of others.

In a globalized world, the tremors of developmental trends can be felt in even the most remote settings. As a result, whether intentional or not, today's local initiatives oftentimes have a broader framework than their pre-globalization era predecessors. Just as women's influence has the potential to envelop an entire community, today, that community in question may also be subjected to the changes of a widening political and social landscape.

There are many advantages to this increased global interconnectivity. For one, it allows for the proliferation of international cooperation in the pursuit of common objectives, like that of GEWE. In fact, many local actors modelled their GEWE frameworks on gender mainstreaming initiatives like that of the UNDP and Canada's Feminist International Assistance Policy (FIAP). Globalization facilitates the creation of platforms of exchange between international institutions and local organizations that enables them to build upon existing frameworks with novel research and capacity-building support. 
This support is greatly aided by the influx of IDVs who contribute to local initiatives through activities geared towards promoting the development of women's leadership. The joint effort of local and international actors adds value to the output of political training that eventually results in an increase of women's political engagement through advocacy, activism and political representation. International volunteers who provide the public platform to expand the reach of local initiatives they are assigned to effectively help amplify the voices of local women, granting them more visibility in spaces where they were otherwise overlooked or invisible.

Yet this ability to reach a wider audience with a higher degree of credibility inevitably comes from the fact that IDVs are often granted the privilege of existing as outsiders, as highly valued contributors to often complex social and political environments. It is for this reason, that local organizers often prescribe a thorough and critical self-reflection of international actors' power and privilege. Specifically, IDVs are asked to revaluate their preconceived notions of 'ideal' development orientations and the ways in which these practices are being implemented in foreign settings. They are asked to expel normative prescriptions from their development agendas in order to objectively assess the needs of local actors in the historical and present context in which they find themselves. In the specific target goal of GEWE, this means doing away with the Western-conceived individualistic conception of feminism and women's empowerment, in order to formulate a more communitarian approach to gender relations (Collier/Muneri 2016). Hence, the need for critical reflexivity among IDVs to more effectively contribute to a transnational feminist vision of development.

IDVs who critically reflect on their positionality in relation to the positions of the people they are intended to support can better identify the root causes of the issues and the practical strategies needed to tackle them. In Kenya, for example, inclusivity in the debate on women's political engagement and empowerment requires a reconfiguration of gender roles and gendered social expectations, which entails the necessary implication of local male actors as well (Collier/Muneri 2016). Likewise, interviewees in Peru highlight the need for an intersectional feminist lens including a deeper understanding of Indigenous women's unique struggle for gender equality, as they simultaneously face gendered barriers within their community and racial discrimination on a national level. Similarly, in Guatemala, critical reflexivity allows international volunteers to get a sense for the unequal relationship that exists between the national government and local population. Ultimately, IDVs' capacity to adopt a critical, objective, and multidimensional perspective on the objectives that local organizations are striving towards reinforces the reciprocity of this international exchange of knowledge and skills.

As IDVs embody reciprocal interactions with local counterparts, these local actors become representatives of their own vision of development by calling attention to 
the causes that affect their communities, which is, in itself, an exercise of political agency. In this way, women who engage in such development activities feel empowered as their own interpretation of reality is valued by their local and international peers. This form of empowerment creates a ripple effect throughout their community, as the empowerment of self provides the tools and creates an opportunity to indirectly or directly empower those around us (Parpart/Rai/Staudt 2002). This also recalls the notion of "the exercise rather than possession of power", which seeks to redefine contemporary power relations by doing away with normative interpretations of effective governance in order to recognize the valuable contributions of non-traditional models of leadership (Parpart/Rai/Staudt 2002: 4).

The capacity building activities local actors participate in with IDVs also coincides with the expansion of their own political output, whether it be through social advocacy or policy prescriptions (Schmid et al. 2008). For instance, this was the case for the partnerships established in Senegal, where IDVs were able to contribute to the formulation of the Additional Act for Equality of Rights between Women and Men within the Economic Community of West African States.

However, the output of women's political engagement remains subjective to the political makeup of their respective regions or countries. In countries like Senegal or Peru where decentralized political structures allow for an explicit differentiation of powers between local and national governing bodies, local governments find themselves lacking the necessary resources to address their respective population's needs and concerns. This is often due to "limited local taxing powers", which prevent local governments from accumulating sufficient public funds to create and maintain public goods and services (Devas 2005: 3).

At the same time, the double burden women carry as both reproductive and productive contributors to society makes them doubly reliant on social services, especially during periods of instability (Tripp 1994). As a result, the quantity and quality of social resources on a local level begin to wane and women are often the first to be affected. In sum, there is an indirect correlation between women's access to social, economic, and political support, or the lack thereof, and their overall community's ability to develop.

In this regard, women's informal labour is crucial to the development of communities that lack sufficient resources from their respective governments. As such, the social servicing provided by informal volunteers enable women to have access to the tools necessary to full and equal participation in governing bodies (Tripp 1994). The fact that women make up a large proportion of these informal volunteering networks means that these networks are more knowledgeable in the specific issues that affect women's livelihood and ability to develop. They become a vehicle of change that mobilizes women in their objective to uplift other women. 
Furthermore, the vertical relationship to power that exists within formal political structures is not always reflective of many women's horizontal relationship to the populations they serve. The findings indicate that despite significant strivings to promote GEWE, these initiatives continue to advocate for women because of the implicit barriers that prevent women from fully engaging and participating in formal party politics; the political authorities that yield the most power within many societies.

The recent legislation that requires women to have an equal representation in political leadership does not always address the root causes of their access to the resources necessary to that ascension to political power. These barriers might include the unequal and gendered division of informal labour and their lack of access to tertiary education, which is often a requirement for many positions of power. This lacuna is the main motivator for many capacity-building activities geared towards the promotion of gender equality. They center the conversation on the need for equity rather than just equality, by addressing the root causes of women's disempowerment in order to enhance the skills, knowledge, and opportunities necessary to their empowerment.

\section{Conclusion}

The form in which women's political participation, activism and advocacy manifests is subject to the local or national political structure, as well as the shifts that take place in their environment. As such, no two models of political mobilization or engagement are the same. Sometimes, the implicit barriers that prevent women from exercising power (i.e., local religious or conservative groups) are particular to the society in question and are imperceptible to the untrained external eye. Hence, the need for international or transnational actors' constant adaptation to local contextual social and political issues.

Transnational relations transcend the limits of international borders and national governance. They encourage individual actors to take initiative and contribute to global development through global cooperation. However, in doing so, international development thinkers and practitioners must also be cognizant of the contextual elements that shape one's positionality and the privilege it may grant them.

Equality does not necessarily imply an erasure of difference. In fact, the universalist approach to international development has the potential to create the opposite effect. The normative prescription of feminist social and political mobilization, or development orientation in a broader sense, has the potential to increase inequality rather than reduce it since the value of a more mainstream perspective could outvalue a more intersectional rationale. In order to avoid this outcome, the 
framework GEWE initiatives must be adapted to the context in which they are being implemented.

In an increasingly globalized world, local issues can take on a global scale, and vice versa. It is therefore important, as transnational cooperation and relationship has proven to continue to build these links through an equitable exchange of knowledge, skills, and power. In the field of international development, many programs, practices, and processes of development have recently been depoliticized in the hopes of promoting a more liberally inclusive approach to global development. Still, the multiple axes of disempowerment or discrimination in many societies continue to pose barriers to equal access to political participation, especially for women.

While depoliticization represents a step in the right direction for the maintenance of global cooperation, the fact remains that the persistence of social issues (as apolitical as they may seem) stem from the excercise of political power, or more specifically, the lack thereof. The achievement of GEWE therefore depends on the achievement of women's political participation in order to draw a more authentic portrait of equitable development - one that considers the voices of all individuals and groups within a society. This entails a global cooperation between IDVs and local actors in their efforts of achieving such a feat, until it ultimately becomes the norm. Since gender equality implies a social shift, women who exercise their political agency and encourage their peers to the same are effectively shifting the power dynamics within their respective social structures.

Women are leading by example by playing an active role in the development of their communities and creating a legacy for future female leaders. IDVs are instrumental to that process. They bring awareness to the causes initiated by local organizations, they offer social support to local actors though mentorship, capacity-building and trainings, and they provide research assistance on local gender-related issues. All in all, their contributions to local development in a variety of global settings represents continuous renewal of transnational cooperation in the noble pursuit of gender equality and women's empowerment.

\section{Bibliography}

Collier, Mary Jane; Cleophas, Muneri (2016): A Call for Critical Reflexivity. Reflections on Research with Nongovernmental and Nonprofit Organizations in Zimbabwe and Kenya. In: Western journal of communication, vol. 80, no.5, pp. 638-658.

Devas, Nick (2005): The Challenges of Decentralization. International Development Department of the School of Public Policy. England.

Kamruzzaman, Palash (2018): Civil Society in the Global South. Abington. 
Lough, Benjamin J.; Carroll, Margaret; Bannister, Thomas; Borromeo, Katrina (2018): The thread that binds Volunteerism and community resilience. 2018 State of the World's Volunteerism Report, https://doi.org/10.18356/14b33d1a-en.

Parpart, Jane L.; Rai, Shirin; Staudt, Kathleen A. (2002): Rethinking Empowerment. Gender and Development in a Global/Local World. London.

Patterson, Amy (2002): The Impact of Senegal's Decentralization on Women in Local Governance. In: Canadian journal of African studies, vol. 36, no.3, pp. 490-529.

Schmid, Hillel; Bar, Michal; Nirel, Ronit (2008): Advocacy Activities in Nonprofit Human Service Organizations. Implications for Policy. In: Nonprofit and voluntary sector quarterly, vol. 37, no. 4, pp. 581-602.

Thraasen, Marianne (2017): Gender Parity in Senegal - A Continuing Struggle. https://papers. ssrn.com/sol3/papers.cfm?abstract_id $=3648097$ (19.08.2021).

Tripp, Aili Mari (1994): Gender, Political Participation and the Transformation of Associational Life in Uganda and Tanzania. In: African Studies Review, vol. 37, no. 1, pp. 107-131. 